central chapters focus respectively on "conventional" and "automatic" methods: the latter "may or must involve calculations . . . so that the use of a computer is usual". Though it perhaps looks sensibly down-to-earth, this is a comparison not of identification methods but of the ways in which we find it convenient to go about them, and it leads to some confusion. Diagnostic keys are "conventional", are they not? But, wait, we can programme computers to construct keys, so that must be "automatic". Matching methods, now these are certainly "automatic": botheration, they have to go in the "conventional" section as well because we can identify by comparison without calculation. And so on, until it must

\section{Ecological methods}

Ecological Methods, with Particular Reference to the Study of Insect Populations. Second edition. By T. R. E. Southwood. Pp. 524. (Chapman and Hall: London, 1978.) £10.

IT is a mark of the uniqueness of this book that in the 12 years since the first edition no competitor volume has emerged that covers such a wide field. Professor Southwood is just as much at home discussing the idiosyncracies of insect trap construction as he is comparing indices of diversity.

The book is well described by its title, and like many compendia will be most useful to the expert or semiexpert. The sort of methods we choose are influenced by our current understanding of the ecological world around us. Nevertheless, in many asides the author does try to redress the balance, pointing out the relative merits of the different techniques, what they can and cannot do. It is here that the book will also be useful to the beginner.

In the past 12 years there has been a dramatic but allometric growth of ecology in two quite different areas. On the one hand the subject has im-

- The US edition of The Climatic Threat by John Gribbin (for review, see Nature, 272, 788; 1978) has been published as What's Wrong with Our
Weather." by Scribners: New York (\$9.95).

O The price of Principles of Cheniral Kinetics (for review, see Nature, 278, $194 ; 1979)$ was incorrectly quoted. This should be $£ 12.65$.

- The US edition of The Visible College bv Gary Werskey (for review see Nature. 276, 136; 1978) will be published in May by Holt, Rinehart and Winston. dawn on the undergraduate or advanced school student that it is identification logic to which he should address himself, not the fuss about computing and programming language (leading, incidentally, to a strange Fig. 18 which actually suggests that "online" is a method of biological identification).

It will be observed that the reviewer has been stimulated. So will be the many others who buy this interesting. thought-provoking volume; they, too. will have to work hard.

\section{J. E. Smith}

J. E. Smith is Professor of Microbiology at the University of Surrey, Guildford. $U K$.

pinged more on public consciousness: on the other, the rapid development of computers and electronic calculators has stimulated much mathematical modelling and analysis. The result is that the scope of ecology and of this second edition is much wider than ever before.

Every chapter has been updated and new sections added, especially on dispersion, capture-recapture methods. components of predator-prey interaction, and dispersal. In particular, recent growth in the methods of construction of life-budgets. systems analysis, descriptions of diversity and species-packing models now allow Professor Southwood to crystallise out a conceptual framework for discussion which was not possible before.

\section{Theoretical astrophysics}

Theoretical Principles in Astrophysics and Relativity. Edited by N. R. Lebovitz, W. H. Reid and P. O. Vandervoort. Pp. 257. (University of (hicago Press: Chicago and London. 1978.) $£ 16.10 ; \$ 23$.

Theoretical Principles in Astrophysics and Relativity offers yet another collection of papers from a conference. this one held in honour of Professor S. Chandrasekhar's 65th birthday in 1975 . I found it a distinct improvement on the usual hotch-potch of disparate lectures re-hashed for the wider public with a minimum of editorial tinkering. Firstly, the book is better produced than most conference reports (which usually resemble a wedge of preprints glued together)- which probably accounts for the immense delay in publication. More importantly, however. the articles are mainly of a review rather than research variety; this is fortunate as nearly four years have
A reviewer must also criticise. The greatly expanded field of the subject (1.000 new references. with few deletions from the first edition) is covered in the space of 130 extra pages. The pace of the discussion is therefore fast and, occasionally, confusing. There are omissions (for example, the log. normal distribution is mentioned twice. on pp33 and 424, without its basic model) and repetitions (for example. equations $2.26,2.27,2.29$ and 2.30 re-appear as equations 2.37, 2.38, 2.41 and 2.42): and occasionally parameters are illdefined (for example. $I_{m}$ of equation 9.28 and $S_{\mathrm{T}}$ of 13.1 ) or, together with variables. given different symbols in the text and figures (for example. $q$ and $Q$ in Table 9.1 and equation 9.6. $N_{E}, N_{k}$ and $P_{k}, P_{l}$ on p382 and Fig. 10.8). Generations of students will now continue to write. incorrectly. of density dependance (Fig. 10.7, in contrast to Fig. 89 of the first edition) and of the Shannon-Weaver rather than Shannon-Wiener function (p426). There are also several small. typographical errors.

None of this. however, detracts from the significant contribution of this volume. The author and publishers are to be congratulated on producing an expanded second edition at less than the price of the final printing of the first. By far the best value on any ecologist's bookshelf.

D. J. Rogers

D. J. Rogers is Lecturer in Entomology at the University of Oxford, UK.

elapsed since the lectures were prepared.

I found the paper on stellar dynamics by Contopoulos especially lucid, and was surprised to see a very formal mathematical paper by Mullikin on the very physical subject of radiative transfer. There is a nice review by Thorne on various phenomena in astrophysics in which general relativity plays a central role. looking all the more relevant with the recent probable discovery of gravitational radiation. The article on singularities in spacetime by Penrose is masterly and thought provoking.

The range of topics covered in the conference was fairly wide, and the articles necessarily somewhat superficial. The book does have. however, a rather more permanent quality about it than comparable proceedings. and is certainly good introductory reading for a host of topics in astrophysics and cosmology. At $£ 16.10$, it is not overpriced for such a well-produced format.

P. C. W. Davies

P. C.W. Davies is Lecturer in the Departmont of Mathematics at King's College. l'niversity of London, $I / K$. 